\title{
SOME FACTORS AFFECTING THE ECONOMICAL MANUFACTURE OF MARINE-ENGINES.
}

By Mr. williai thomson, of Glasgow.

The most desultory reader of our technical journals cannot fail to be struck with the great and increasing interest which has of late years been taken in the internal economy of our engineering workshops. The object of this Paper is to draw special attention to certain factors affecting this economy, which have hitherto not received the consideration that their importance warrants. Into the subject of commercial organisation of engine works, or the strictly on-cost factors, it is not intended to enter, but instead, to touch upon certain factors, which directly affect the workshop itself, and have a distinct influence upon its productive capacity. The interest which is spreading in regard to workshop economies is one of the most hopeful signs that an awakening to the new order of things is taking place. Manufacturers are becoming alive to the fact that it is necessary nowadays for a closer and more personal interest to be taken in the minutest and, apparently, most trivial details of workshop practice, and are forced to consider certain influences, some of which have been looked upon as outside the range of practical workshop economics, or at most have received a qualified or indifferent approval. 
There is a wide and interesting field in every workshop for him who makes these his special study, but it requires continuous and concentrated attention to obtain the best results. The points particularly referred to are-

(1) A premium system of labour remuneration.

(2) Good, accurate, and powerful tools.

(3) Arrangement of tools and roomy shops.

(4) Clean and tidy shops.

(5) Well lighted and well warmed shops.

(6) Standardisation.

The Premium System.-The first and greatest of all these influences is the introduction of the Premium System, which effects nothing short of a complete revolution in a shop, and its consequences are very wide and far reaching indeed, and in directions which at first sight might seem to have no connection with the source.

One of the primary results of the premium system is the establishment of accurate data, upon which comparisons can be based and deductions made. It is hardly possible to overestimate the benefits of having accurate and reliable detailed data in the works as a means of comparison, yet this is often overlooked or ignored, and the comparatively small sum per annum, which the establishment of an efficient time or records office in the works would cost, is grudged, because the profitable return which such an investment would give, if properly worked and managed, is not realised.

The revelations, which would be made by the introduction of such an office in any place previously without one, would be sufficiently convincing to most engine builders, yet lethargy or indifference keeps many from availing themselves of a means of speedily infusing new vitality into their place, and starting afresh with renewed youth and vigour. There is no doubt that it requires an amount of faith and the whole-souled energetic personal attention of a principal or highly-placed official to introduce such a system. The necessary work takes a large amount of time for a 
considerable period, but the results are worth it all, and once the system is started and in fair working order there will be no looking back. Table 1 (page 886 ), columns 1 and 2 , gives a few examples of what the premium system has done in the way of economising time.

Apart, however, from the question of economising tine, the system provides an admirable and efficient check upon any oxcessive rise in wages cost, as each contributory cause becomes apparent, and can be investigated the moment it arises, and suitable means taken to prevent a recurrence in future. The knowledge that such variations above the normal in the time taken are investigated in detail and checked, acts in a most wholesome manner upon the men and foremen, keeping them alert and tending to produce an even and gradually increasing average of performance.

Accurate and Poverful Tools.-Another most important factor in the economical production of work, is good, powerful, and, very especially, accurate machine tools. This is axiomatic. Everyone acknowledges this, but how many builders even yet realise exactly what this means, or can state in reliable figures the actual difference between one tool and another in output, which, after all, is the real basis of comparison. Had they been able to do so, the wave of revival and re-organisation now setting in would have commenced far earlier than it has done, and a vague and hesitating belief in the need for new and up-to-date tools gradually taking the place of a hitherto blind confidence in old and cherished machinery, would have speedily grown into strong conviction, when backed by the hard facts of accurate and reliable data of comparison.

The experience of the author's firm in this direction has been one of considerable extent. Old tools which were formerly thought to be doing fairly good or average work on the whole were found to be hopelessly wanting in speed, handiness, and principally accuracy and power; within the last few years nearly the whole of these machine tools have been sold or otherwise disposed of, and new and more powerful machinery substituted.

'The Premium System had not been very long started before it began to show up some very great discrepancies in the performance of 
TABLE 1.

\begin{tabular}{|c|c|c|c|c|}
\hline \multirow[b]{2}{*}{$\begin{array}{l}\text { Description of } \\
\text { Work. }\end{array}$} & \multicolumn{4}{|c|}{ Same Machines throughout. } \\
\hline & $\begin{array}{c}(1) \\
\text { Time taken } \\
\text { under old } \\
\text { Time System. }\end{array}$ & $\begin{array}{l}\text { Time taken on } \\
\text { introduction } \\
\text { of Premium } \\
\text { System. }\end{array}$ & \begin{tabular}{|c|}
$(3)$ \\
Time taken in \\
better location \\
with greater \\
facilities.
\end{tabular} & $\begin{array}{l}\text { Record time } \\
\text { for the } \\
\text { same job. }\end{array}$ \\
\hline \multirow{3}{*}{$\begin{array}{l}\text { 1. Turning conn. } \\
\text { rod. } 1 \text { off. } \\
\text { 2. Slotting conn. } \\
\text { rods. } 3 \text { off. } \\
\text { 3. Crank webs } \\
\text { (finishing holes. } \\
1 \text { off). }\end{array}$} & $\begin{array}{c}\text { hours. } \\
43 \frac{1}{2} \\
31 \\
7 \frac{3}{3}\end{array}$ & $\begin{array}{c}\text { hours. } \\
36 \\
24 \frac{1}{2} \\
5 \frac{1}{2}\end{array}$ & $\begin{array}{c}\text { hours. } \\
35 \\
22 \frac{1}{4} \\
4 \frac{3}{4}\end{array}$ & $\begin{array}{c}\text { hours. } \\
291 \\
20 \\
\\
3_{2}^{1}\end{array}$ \\
\hline & \multicolumn{2}{|c|}{ Old Machines under } & \multicolumn{2}{|c|}{$\begin{array}{c}\text { New and more powerful } \\
\text { Machines (on Premium } \\
\text { System). }\end{array}$} \\
\hline & $\begin{array}{l}\text { Old Time } \\
\text { System. }\end{array}$ & $\begin{array}{l}\text { Premium } \\
\text { System. }\end{array}$ & $\begin{array}{l}\text { First time on } \\
\text { new Machine. }\end{array}$ & Record 'Time. \\
\hline $\begin{array}{l}\text { 4. Turning tunnel } \\
\text { shafting. } 1 \text { off. }\end{array}$ & $\begin{array}{l}\text { hours. } \\
42\end{array}$ & $\begin{array}{l}\text { hours. } \\
293\end{array}$ & $\begin{array}{c}\text { hours. } \\
23 \frac{3}{3}\end{array}$ & $\begin{array}{l}\text { hours. } \\
21\end{array}$ \\
\hline $\begin{array}{l}\text { 5. Turning ecc. } \\
\text { rode. } 1 \text { off. }\end{array}$ & 22 & $11 \frac{1}{2}$ & 9 & $8 \frac{1}{4}$ \\
\hline $\begin{array}{l}\text { 6. Turning thrust } \\
\text { shaft. } 1 \text { off. }\end{array}$ & 129 & $97 \frac{1}{4}$ & 75 & 65 \\
\hline $\begin{array}{l}\text { 7. Finish turning } \\
\text { crank shaft. } \\
1 \text { off. }\end{array}$ & 42 & 34 & 15 & 98 \\
\hline $\begin{array}{l}\text { 8. Turning quad. } \\
\text { blocks. } 13 \text { off. }\end{array}$ & 195 & 140 & $91 \frac{1}{4}$ & $90 \frac{1}{2}$ \\
\hline $\begin{array}{l}\text { 9. Slotting sole- } \\
\text { plates. } 1 \text { off. }\end{array}$ & 70 & 591 & $41_{\frac{1}{2}}^{2}$ & $35 \frac{1}{4}$ \\
\hline $\begin{array}{l}\text { 10. Slotting con- } \\
\text { denser. } 1 \text { off. }\end{array}$ & $6 t$ & 56 & 44 & 34 \\
\hline $\begin{array}{l}\text { 11. Slotting H.P. } \\
\text { cylinder. } 1 \text { off. }\end{array}$ & $45 \frac{3}{4}$ & 33 色 & 24 & 21 \\
\hline $\begin{array}{l}\text { 12. Ripping out } \\
\text { holes in crank } \\
\text { webs (1 web) } \\
2 \text { holes. }\end{array}$ & 29 & 17 & 9 & 7 \\
\hline $\begin{array}{l}\text { 14. Hole - boring } \\
\text { main bearing } \\
\text { covers for bolts. } \\
12 \text { holes. }\end{array}$ & 45 & 37 & $27 \frac{1}{4}$ & 20 \\
\hline $\begin{array}{l}\text { 15. Planing six } \\
\text { steel slabs for } \\
12 \text { crank webs. }\end{array}$ & $142 \frac{1}{2}$ & 102 & $6 \tilde{5}_{4}^{1}$ & $65 \frac{1}{4}$ \\
\hline
\end{tabular}


similar tools when on the same work. This led to an investigation of the causes, and generally it was found that the result was due to the weakness or want of power of the less efficient tool. Indeed, so frequently was this particular fault of weakness or want of power found to exist, that the limit of output was very soon reached, and in order to overcome this, all the work had to be moved up a stage or two, and a heavier class of tool used, in order to get more power for the heavy cutting, which the Premium System developed. This led to congestion in the work for the heaviest tools, so newer and more powerful ones all along the line were substituted as soon as possible. A few examples of the results of this substitution are given in Table 1, by comparing columns 2 and 3 .

The high cutting-speeds, which have lately been introduced since the Bethlehem Company raised the question, have very much increased the stress on lathes and boring machines, and have rendered powerful and substantial machines a greater necessity than ever. Generally speaking, in machines of this class cutting power is not in proportion to capacity, and want of belt power is a fault more often met with than not in machines of all classes. A certain tool made by a first-class firm was purchased by the author's firm three years ago, and after repeated trials it was concluded that it had not adequate belt power, so when a second machine was ordered, an increase in the ratio of gearing of about 28 to 30 per cent. was insisted upon, much against the will of the toolmakers, who considered that the first machine was amply powerful. The result is that the newer machine turns out the same work as the old in $26 \cdot 5$ per cent. less time.

Arrangement of Tools and Roomy Shops.-The questions of arrangement of tools and roomy shops are closely connected and interdependent, and where these have to be applied to existing buildings they become very difficult ones to settle; in most cases the result cannot be anything more than a compromise, because, for a given sequence of operations to be carried on within a given crane area, certain tools are required, and roominess around each tool cannot be given without affecting the arrangement of the tools, 
probably to the extent of excluding some of them altogether from the building, and thus breaking the sequence of operations by extra handling. When, however, new shops or extensive alterations are about to be entered upon, the question deserves the most serious consideration. The comfort and convenience of having ronmy machine shops is another condition very difficult to put a money value upon; but those who have had to deal with overcrowded machine shops, where a large proportion of floor space is taken up by tools or by the work for them, realise the great inconvenience and discomfort caused by this, and must see that money is being lost under such an arrangement. Plenty of room should be allowed round each tool, and this applies in a greater degree to heavy machine-tools than to light, because these have to deal with much heavier and more bulky pieces which cannot be easily handled or transported from spot to spot, and aro generally stacked around or near the machines which operate on them.

The question of handling of material, which is the direct result of the arrangement of tools, is one' which has not received the attention it deserves, simply on account of the difficulty of getting at the direct loss caused by a poor arrangement, even if it is realised that a loss is taking place; and experiments are tedious and expensive. There is no doubt; however, that much ean be done in this direction in the marine-engine shop, if these questions be properly investigated.

As an example of what can be done by the consideration of these questions, it might be mentioned that after the author's firm laid down their new boiler shop, the work turned out by the light and heavy plating squads was done in 19.6 per cent. less time in the new shops than it had averaged in the old, while the machines turned out their work in 10 per cent. less time than before; the conditions in both cases as regards tools and appliances being exactly the same, except that more room was allowed.

Another example taken from the machine shop illustrates this same point very well. A group of three machines was located in the old machine shop in somewhat cramped and inconvenient positions, but afterwards these machines were shifted to a new 
machine-shop and given ample room. The results of this new arrangement are given below in Table 2 :-

TABLE 2.

\begin{tabular}{|c|c|c|c|}
\hline \multirow{2}{*}{ Machine. } & \multicolumn{2}{|c|}{ Saving. } & \multirow{2}{*}{$\begin{array}{l}\text { Output } \\
\text { increased by }\end{array}$} \\
\hline & Time. & Money. & \\
\hline $\begin{array}{l}\text { Double - headed Horizontal } \\
\text { Borer. }\end{array}$ & $\begin{array}{c}\text { per cent. } \\
3 \cdot 9\end{array}$ & $\begin{array}{c}\text { per cent. } \\
2 \cdot 5\end{array}$ & $\begin{array}{c}\text { per cent. } \\
4\end{array}$ \\
\hline H. and V. Planer & $22 \cdot 5$ & 14 & 29 \\
\hline Connecting-rod Lathe. & $12 \cdot 8$ & $8 \cdot 3$ & $14 \cdot 7$ \\
\hline
\end{tabular}

In this comparison the conditions were as nearly as possible the same in both cases; the machines doing the same kind of work, the same men were at the machines, and were working under the premium system in the new shop as in the old. The result was that the men made on an average - which is taken over a long period in both cases $-9 \cdot 3$ per cent. more wages, the work was $8 \cdot 3$ per cent. cheaper to the firm, and $15 \cdot 9$ per cent. more work was got out of the same machines, due entirely to a better arrangement and more roomy location of these machines. This example is only one of many which could be given, but serves to bring out the points which have been mentioned.

Clean and Tidy Shops.-With regard to clean and tidy shops it is the belief of the author's firm-and they are encouraged in this by experience and example of the most progressive shops-that these do pay; yet are not dirty, dark, untidy, cold and badly arranged shops met with in this and other countries, turning out good work, which must cost, and is costing, more than it might, simply on account of these drawbacks. That such conditions are allowed to continue is due either to indifference or ignorance of better, on the part of the responsible management, or if they realise the benefits of having better conditions, they lack the necessary courage or perseverance to 
put an end to the old bad ones. The value of having clean, tidy, well-lighted and warmed workshops is one which it is impossible to determine in money, but that it does have an actual and very real and substantial value is the belief and experience of all those who have embodied these conditions in their workshop practice, and there are now many examples of this belief.

One cannot have a clean shop which is not a tidy shop, and neither will be found in a badly-lighted shop. The author's firm set out to improve on these lines by first getting rid of the old earthen floor which is so common, and by laying the whole of the ground floor with granolithic and concrete parement. The improvement is most marked; formerly with the old earthen and iron-chip floor it was impossible to keep anything clean. Dirt and dust were the order of the day if the floor had to be swept, so it was generally left alone as long as it could be tolerated. Now there is no trouble, but instead a fine, smooth, clean, bright surface to move about on. The floor is from 9 inches to 12 inches thick in most places, and below machines somewhat thicker, and consists of about 2 inches of rough bottoming of broken stone, then 6 inches of concrete of 5 to 1 , and a top finish 2 inches thick of facing made of granite chips and cement in the proportion of $1 \frac{1}{2}$ to 1 . As it sets, it is levelled and smoothed off with a trowel and in three days is ready for use, becoming quite hard in about a week, and when thoroughly set the floor assumes a beautiful white surface which has the effect of reflecting the light and perceptibly aiding the general lighting of the shop. Although somewhat dearer than other styles of flooring, there is none other which possesses so many advantages. It has a fine, bright, smooth surface, and is therefore easily swept and kept clean, is easily repaired, and does not wear into hollows like wood paring, and there has been no complaint from the workmen about it being sore to the feet.

Well Lighted and Well Warmed Shops.--The benefits of having a weil lighted engine and boiler shop are pretty generally recognised, but not to the extent they might be. There are still far too many places-some of them of first rank-without adequate means of 
lighting, struggling along with lucigen lamps or gas in an almost Stygian darkness, which can only be dispelled by electric light and plenty of it. This is more generally the case in boiler shops than in machine shops, and, if there is a place where there ought to be good light, it is in a boiler shop. The amount of time lost by men cautiously feeling their way about in somi-darkness, coupled with the time lost by skulkers and loafers dawdling away their time in dark corners, is very considerable; besides which, men very naturally dislike having to work in a dark shop, and their unwillingness affects their attendance, and they lose time.

Owing to certain circumstances the new boiler shop electric light installation was not in working order until the winter season was half through, yet from the day the current was switched on the boilermakers' attendance improved, and, while the average time lost before the introduction of electric lighting was $14 \cdot 72$ per cent., after the light was introduced the time lost averaged $13 \cdot 2$ per cent., a distinct saving of over 1.5 per cent., or three-quarters of an hour per week per man. This is attributed solely to the lighting of the shop. The difference in other directions is most marked. The men can move about with freedom and decision, there are no dark corners, the time workers have not the same temptation to waste their time, and managers and foremen can see what is going on from end to end of the shop with the utmost distinctness. Table 3 (page 892) gives a comparative statement of the various shop lighting.

With regard to the warming, this is a problem which has given the firm much thought for some time back, but as yet no definite decision has been come to in the matter. The range of temperature is not nearly so great in this country as in the United States and Germany, and the want of proper heating facilities does not become one of daily experience, hence probably the reason why so little has been done in this direction. Nevertheless, there cannot be any doubt that as a rule engineering workshops in this country fall very short in this direction. The idea which used to be very prevalent, especially in boiler-making lines, that a cold snap made men work all the harder in order to keep themselves warm, is happily exploded, and a more rational view is now being taken of this hitherto much 
neglected subject. How is it to be expected that work, and especially good work, is to be got from men whose hands are chilled to the bone, and while the main energies are naturally taken up with means of keeping up their circulation.

TABLE 3.

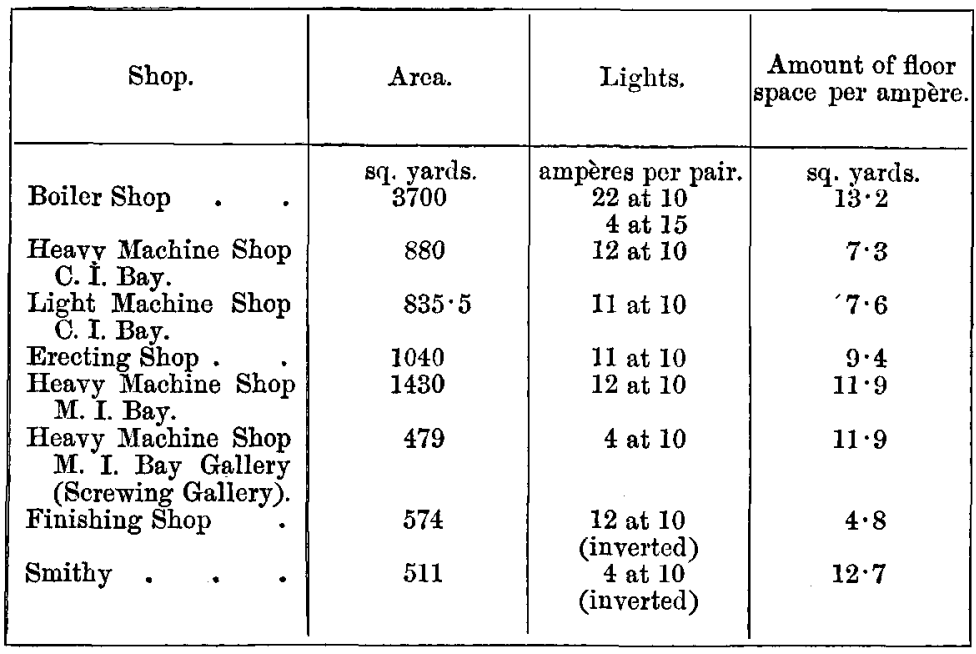

Voltage 110. Körting and Mathieson.

Standardisation.-The Premium System, with its attendant records, very soon showed up the benefits of having duplicate work, as the saving of time was quite considerable where a run of duplicate or nearly similar pieces was given to a machinist. This was so marked that the question of standardising, not only the details, but the whole engine, was gone into, in order to get the full benefit of this, and as patterns began to require renewal the engine was redesigned with this end in view. In carrying out this idea in a new design it was found necessary, not only to consider the engine and its details in relation to themselves alone, but also with special regard to their position in the range of sizes which it was decided to make, with a view of keeping down the number of different sizes of details. The question instantly became one not only affecting the 
whole range of engines made by the firm, but also their practice in connection therewith. This practically meant redesigning simultaneously all the sizes of engines made; but a careful analysis and consideration of the requirements to be met enabled the whole range to be suitably broken up into well defined groups, each group representing a certain size of main centres and permitting certain variations of cylinder diameter and stroke within well defined limits, and suitable for the usual steam-pressures. The details-which in each group are never altered although the cylinders may vary within the group limits-are in very many cases common to several groups, and a large number common to the whole range. This object is always kept in view, in order to provide as much duplicate work as possible. Especially is this so in the case of the very small and numerous details, because in these the governing factor in the cost is the wages, not the material; a slight and unimportant variation in size causes a relatively large variation in wages cost, while in the larger details the conditions are reversed and the material becomes the important cost factor, a relatively small variation in wages covering a very large variation in size. The location of the dividing line between these two conflicting sets of conditions thus becomes a matter of considerable importance, but the accurate data from the time-office enables its position to be fixed with great exactness, so as to allow of as much duplication of parts as will pay.

When, however, duplication of pieces can no longer be carried out on account of the cost of material prohibiting it, much can be done in the way of duplicating similar machined, faced, etc. parts, in different groups. This enables and encourages the use of jigs, which, under other conditions, would not have been warranted by the saving in wages. When even this cannot be done, standardisation by a graded series of similar pieces does much to make the progress of the work through the drawing office and the shops easy and free from the friction and delay incidental to sudden and abrupt changes in design. In the drawing office it has the effect of crystallising that vague thing known as "our practice," and compels it to carry out its work on well defined lines, thus avoiding 
expensive and irritating changes and mistakes or oversight. It has also the effect of economising draughtsmen's time, as a standard series of drawings once properly arranged do not require to be redrawn for every new job.

In the shops, standardisation by its consistency in design familiarises the staff and men with the practice, and enables them to go about each new job with confidence and expedition, knowing that each job as it comes forward, if not a duplicate, will at least be similar, all of which go far to speed up the progress of work through the shop and thus increase the output. And above all, by the very fact that the means to effect this calls for the best facilities and most exact workmanship, the result is that the character of the workmanship is raised besides being cheapened, with satisfactory results to both consumer and manufacturer.

[Note.-The discussion on this Paper was combined with that of Mr. Rowan's and Messrs. Weir and Richmond's Papers, and commences on page 907.$]$ 